\title{
Acculturation and Social Support in Relation to Psychosocial Adjustment of Adolescent Refugees Resettled in Australia
}

\author{
Lydia Kovacev \\ and \\ Rosalyn Shute \\ School of Psychology \\ Flinders University \\ South Australia
}

Key words: adolescence, acculturation, social support, refugees, psychosocial adjustment

Correspondence during 2003 to: Rosalyn Shute, PhD, School of Psychology, Flinders University, GPO Box 2100, Adelaide 5001, South Australia.

Email: ros.shute@flinders.edu.au

Correspondence from January 2004 to: Prof. Rosalyn Shute, $\mathrm{PhD}$, Discipline of Psychology, School of Behavioural and Social Sciences and Humanities, University of Ballarat, Mount Helen Campus, PO Box 663, Victoria 3353, Australia.

(I do not have an email account there as yet, but will still be contactable through my Flinders email address). 


\begin{abstract}
This study examined how different modes of acculturation and perceived social support are related to adolescent refugee psychosocial adjustment, as measured by global self-worth and peer social acceptance. The 83 participants, aged between 12 and 19, were from the former Republic of Yugoslavia, now resident in Australia. Those who had the most positive attitudes toward both cultures obtained the highest ratings of self-worth and peer social acceptance. In contrast, those who had negative attitudes toward both cultures had the lowest scores on these measures of psychosocial adjustment. Results were consistent with the proposition that the effects of acculturation on adjustment are mediated by peer social support.
\end{abstract}


Refugees resettling in a new country face many challenges. For adolescents, these challenges may be especially great, as the non-normative experience of migration is superimposed upon a complex of normative changes such as puberty, a developing sense of identity and the renegotiation of earlier parent-child relationships (Myers, 1999). Migration adds complicating factors such as cultural changes, the loss of former social relationships and the need to form new ones. This study focused upon peer relationships, examining how the psychosocial adjustment of adolescent refugees, in terms of global self-worth and peer social acceptance, is related to acculturation and social support. The context for the study was migration to Australia during the 1990s as a result of civil war in the former Yugoslavia; we will explain the background of our adolescent participants before detailing the rationale for this study.

The adolescents were all born in the former Yugoslavia. The majority were of mixed ethnicity, their families typically coming from the multiethnic and multicultural communities typical of large cities such as Sarajevo. They had all been brought up to identify themselves as Yugoslavs, under a Communist government. They all spoke the same language and were exposed to the same curriculum at school. Civil war broke out in Yugoslavia in April 1992. This was a complex war, fought not only along various ethnic lines, but between different, multiethnic political groups.

Previous research by one of us with this population indicates that the most commonly experienced life events after this date included confiscation of all property, bombing and shelling, being expelled from home, death of a family member, witnessing killing or torture, and being verbally threatened (Kovacev, 1994). Similar histories have recently been obtained from Bosnians resettled in Australia (Momartin, Silove, Manicavasagar \& Steel, 2002). Participants’ families had migrated to Australia after the outbreak of war through either the Special Humanitarian Program 
or Special Assistance Category, programmes organised by the UNHCR (Department of Immigration and Multicultural Affairs, 1998). Two of the most commonly stated reasons for entry through these programmes are: being in nationally mixed marriages and persecuted in the country of origin and/or; one or both partners being ex-prisoners of war. The majority sought refuge in a number of different shelters before migrating to Australia. The pre-migrational experiences of these young people were therefore very similar to one another, in being brought up under a single regime and then sufferering the traumas of war and the refugee experience.

The focus of the present study, however, was on post-migrational experiences, i.e., following resettlement in Australia. This was determined partly by ethical concerns about questioning young people about trauma, but also by recent findings that post-migrational experiences may be better predictors of psychological difficulties and adjustment problems than pre-migrational experiences (e.g., Liebkind, 1996; Pernice \& Brook, 1996). The purpose of the present study was specifically to examine adolescents' adjustment in relation to acculturation and social support, with a particular emphasis on peer relationships in the adopted country.

Normative developmental tasks in adolescence include developing a sense of identity and establishing attitudes towards other groups (Branch, 1999). These tasks are arguably even more salient and complex for adolescents who have been forced, by circumstances of war, to begin life afresh in a new country. For example, even if issues of ethnic identity had previously been diffuse (that is, not actively considered; e.g., Phinney \& Alipura, 1990), contact with others in a new country inevitably raises issues of ethnic identity and ethnic group differences. This is the case for minority youth in general, whose adjustment is related to how successfully they manage the 'multiple worlds’ in which they exist (Cooper, Jackson, Azmitia \& Lopez, 1998). 
Similarly, on arrival in a new country, young refugees are faced with multiple worlds and have the task of negotiating the process of acculturation: that is, how (and, indeed, whether) to make attitudinal and behavioural changes as a result of exposure to the host culture. Later, we discuss in more detail the different ways in which acculturation may occur.

There is a well-established association between the quality of young people's peer relationships and their adjustment, both concurrently and in the longer term. Adolescence is a time when the peer group becomes increasingly important, fulfilling functions such as providing support, companionship, a sense of identity and experience with the opposite sex. The migration experience at this key developmental period may be particularly disruptive in this regard, and those who migrate in adolescence have fewer friends (as adults) than those who migrate in childhood or adulthood (Myers, 1999). At the same time as they are facing a complex of other normative and non-normative changes, these young people face the (probably total) disruption of their previous peer support networks and must therefore start afresh. Furthermore, most of the peers available to them are schoolmates from the host culture, creating potential difficulties as a result of language and cultural differences. Therefore, as we discuss below, we can expect acculturation, peer social support and adjustment to be intertwined for these young people.

A large number of studies has been conducted in the areas of acculturation, social support and self-esteem (the latter being considered a general measure of adjustment); however, few have been carried out with adolescent refugees or migrants. Most are of an epidemiological nature (e.g., Sack, Clarke \& Seeley, 1997), or explore cultural differences evident in cultural norms, values and practices (e.g., Georgas, Berry, Shaw, Christakopulou \& Mylonas, 1996; Nguyen \& Williams, 1989; 
Roer-Strier, 1996; Rosenthal, Ranieri, \& Klimidis, 1996). Also, such studies have generally been conducted within European or American cultural contexts, societies that perceive acculturation in terms of a continuum from ethnic retention to assimilation (Gans, 1997; LaFromboise, Coleman \& Gerton, 1993); as discussed below, this view does not capture the range of modes of acculturation which individuals might adopt. Furthermore, studies are largely confined to investigating the relationship between two variables (e.g., Phinney, Chavira \& Williamson, 1992). Klimidis, Stuart, Minas and Ata (1994) have noted that mental health outcomes for migrant groups are multifactorially determined, and studies need to reflect this.

Sam and Berry (1995) examined both social support and acculturation attitudes in adolescent migrants in relation to self-esteem: they found that interpersonal relationships (close contact with parents and number of friends) and acculturation attitudes contributed independently to variance in global negative selfevaluation. Their study was carried out in Norway, a monocultural society. In the present study, the relationship between acculturation attitudes, perceived social support and psychosocial adjustment in young refugees was examined in Australia, a society that endorses multicultural policy and thus potentially provides refugees with more options for adapting to their new environment. (N.b. Since this study was carried out, the Australian Government has received much criticism at home and overseas for its treatment of refugees in detention centres; however, it remains the case that, for those who eventually enter the Australian community, a multicultural environment exists, with many special services provided for refugees and other migrants.) 


\section{$\underline{\text { Acculturation }}$}

Acculturation may be defined as behavioural and psychological changes that occur as a result of contact between two different cultures (Sam \& Berry, 1995). These changes significantly affect a person’s ethnic identity, behaviour patterns, values and attitudes (Kwon, 1995). The term acculturation is often used to define changes that occur in members of a minority group in contact with another dominant culture. Berry, Kim \& Bosky (1988) suggest that acculturation is a process by which individuals change their psychological characteristics or change the environment or amount of contact with others in order to achieve a better outcome in the context in which they live. This study explored acculturation attitudes: they are regarded as core elements of ethnic identity in comparison with more readily adopted behaviours (Rosenthal \& Feldman, 1992) and, as mentioned previously, establishing an identity is a key task of adolescence. The exploration of acculturation attitudes is particularly important in culturally plural societies such as Australia in which a person is given the opportunity to re-evaluate his or her original cultural identity as a result of exposure to the host culture. While Australia's multicultural society supports the maintenance of original ethnic links, resettled adolescent refugees also come into frequent and regular contact with the host culture through the school system, of which their Australian peers are an integral part.

Berry (1984) has developed a model of four distinctive modes of acculturation, equivalent to a 2 x 2 combination of level of identification (high /low) and culture (native/host).

Assimilation occurs when a person does not want to maintain his or her distinct ethnic identity and is willing to accept values and customs of the host culture. 
A person may be absorbed by an established dominant group or a society may encourage merging to form a new national identity (melting pot).

Integration occurs when a person maintains his/her native cultural identity at the same time as participating in the host society.

The third mode of acculturation is when a person values the maintenance of his or her own ethnic identity, but participates minimally in the host society. When the dominant culture adopts this position, segregation takes place "to keep minorities in their place”. However, if the decision to keep one’s distance from the host culture is made by the ethnic group, this is referred to as separation, which leads to insular existence of a minority group.

Marginalisation involves rejection of both one's own ethnic identity and the host society and is associated with personal confusion, anxiety and alienation.

Several recent studies show a positive relationship between assimilation and self-esteem (Flaskerud \& Uman, 1996; Huang, Leong \& Wagner, 1994; Padilla, Wagatsuma \& Lindholm, 1985). In contrast, Phinney, Chavira and Williamson (1992) reported that endorsement of assimilation was related to lower self-esteem among foreign-born adolescents of mixed background resettled in the USA. Furthermore, some studies have failed to find any significant relationship between self-esteem and acculturation (Orshan, 1996;Yu \& Berryman, 1996). These rather inconclusive results may be due to differences in definitions and models of acculturation. For example, studies that define acculturation as just another word for assimilation do not adequately discriminate those who are positive toward both cultures from those who are only positive toward the new culture.

In contrast, within Berry's model, assimilation is only one way of acculturation in addition to integration, separation and marginalisation. The empirical 
evidence indicates that these modes of acculturation are differently related to psychosocial adjustment. In several studies integration has been shown to promote the best way of adjustment to a new culture and marginalisation the least adaptive way (Berry, Kim \& Boski, 1988; Liebkind, 1996; Sam \& Berry, 1995). In respect to separation, the literature suggests that this provides temporary protection, but that there are long-term risks if a person fails to interact with the society at large (LaFromboise, Coleman \& Gerton, 1993; Phinney, Lochner \& Murphy, 1990).

In addition to personal preferences and values, the mode of acculturation will be influenced by national policies endorsed by the host society. A society that encourages multiculturalism, such as exists in Australia, will provide more options for adaptation than a society that encourages only one mode of acculturation (Berry, Kim \& Boski, 1988). Since 1973, Australian Federal Governments have endorsed a policy of multiculturalism to promote unity within the nation's cultural diversity. Although it has become a contentious political issue in recent years, with diverse opinions about its meaning, multiculturalism is a policy supported by the major political parties (Jenkins, 1997). A multicultural society has been defined as a society whose groups co-exist, free to maintain many of their distinctive religions, linguistic services, civil rights and political power while sharing with the rest of society particular values which have a national significance (Grassby, 1973). Australian Governments have recognised the need to cater for the special needs of migrants settling into a new culture by providing services such as Migrant Centres and grants-in-aid to ethnic communities (Office of Multicultural Affairs, 1988). Consequently, Australia’s multicultural policy places relatively little pressure on newly arrived migrants to assimilate, creating more options and alternative ways for them to determine how and when they will form their new cultural identities. 


\section{Global Self-Worth}

Global Self-Worth (GSW) was used in this study as a measure of psychosocial adjustment. Terms such as self-esteem, self-concept, global self-worth and global self-esteem are often used as synonyms, although some authors try to define conceptual differences (Pope, McHale \& Craighead, 1988). The present study adopted Harter's definition of global self-worth (GSW) as “the degree to which one likes oneself as a person, likes the way one is leading one's life, is satisfied with oneself, in general is happy with the way one is.” Since GSW represents general feelings of worth as a person, it can be considered a measure of psychosocial adjustment (Klimidis, Stuart, Minas \& Ata, 1994). GSW was measured in this study by the Adolescent Self-Perception Profile ("What I am Like”) (Harter, 1988).

\section{Peer Social Acceptance}

As the study had a focus on peer relationships, the social acceptance scale of the Adolescent Self-Perception Profile (Harter, 1988) was also used as a measure of psychosocial adjustment. Harter defines social acceptance as the degree to which the adolescent feels popular among peers, has lots of friends and feels that he or she is likeable the way they are. It has been argued that social acceptance during preadolescence has important implications for adaptive adjustment later on in adulthood as confirmed in a recent 12 year longitudinal study by Bagwell, Newcomb \& Bukowski (1998). Furthermore, research conducted by Hurtado and Carter (1997) has found that social acceptance plays an important role in helping minority students to integrate and adjust to college.

\section{$\underline{\text { Social Support }}$}

Harter defines social support as the positive regard received from others (Harter, 1985). Adolescents are asked to assess how much others appreciate them as a 
person, show understanding, care for their feelings, and are available to listen to their problems. A number of studies conducted on children and adolescents indicate that social support is an important resource that has a protective effect against stress (Garmezy, 1983; Sandler, Miller, Short \& Wolchik, 1989; Werner \& Smith, 1982) and, for Australian preadolescents, social support satisfaction is predictive of GSW (Shute, DeBlasio \& Williamson, 2002). Recent research by Flaskerud and Uman (1996), conducted with a group of migrants, examined the relationship between selfesteem and demographic factors, acculturation, and social support. The results indicated that increases in cultural assimilation were followed by increases in selfesteem, over the period of one year; this suggests a causal effect of acculturation on adjustment. Others have found positive correlations between acculturation, social support/social integration and subjective reports of well-being (Cheung, 1995; Dona \& Berry, 1994; Sasao \& Chun, 1994).

Social support was measured in this study by the Social Support Scale for Children (Harter, 1985). This identifies four separate sources of positive regard: parents, classmates, close friends and teachers. In this study the teacher support scale was not used, as Harter (1985) indicated that the importance of teachers' support decreases while the importance of having support from close friends increases as children move to adolescence. The parental support scale assesses the extent to which parents understand and listen to their children's problems and care about their feelings. The two remaining scales of social support assess two different kinds of peer support: classmate and close friend support. The classmate support scale examines the degree to which one feels accepted as a friend in general. The close friend scale assesses whether a youth has close intimate friendships. 
The Social Support Scale for Children was normed on a group of youths attending middle schools in the USA, grades 6 through 8 (12 to 14 year olds). Although the scale was not administered to groups of older adolescents there are no evident limitations on using it with an extended age range. Furthermore, normative data were not of relevance in the present study (these would in any case need to be treated cautiously given the special population in the present study). The Present Study - Model and Hypotheses

On the basis of the literature reviewed above, a guiding model for the present study was developed (Figure 1). The measures addressed are indicated by bold letters.

\section{Figure 1 about here}

The purpose of the present study was to investigate the effects of acculturation and social support on psychosocial adjustment as measured by global self-worth and peer social acceptance. It was hypothesised that:

1. Acculturation will predict a young person's sense of global self-worth (GSW). However, the strength and direction of the relationship between acculturation and GSW will vary depending on the type of acculturation. It is hypothesised that the correlation coefficients between acculturation level and GSW will be in the following order: acculturation through integration (strongest positive correlation coefficient), acculturation through assimilation, acculturation through separation, and acculturation through marginalisation (strongest negative correlation coefficient).

2. Acculturation will predict Peer Social Acceptance (PSA). However, the strength and direction of the relation between acculturation and PSA will vary depending on the type of acculturation. Specifically, it is hypothesised that the correlation coefficients between acculturation level and peer social acceptance will be in the following order: acculturation through integration (strongest positive 
correlation coefficient), acculturation through assimilation, acculturation through separation, and acculturation through marginalisation (strongest negative correlation coefficient).

3. Social support (parent, classmate and close friends support) will be positively correlated with GSW and PSA such that higher levels of perceived support (from all three sources) will be associated with higher GSW and PSA scores.

4. In addition, the relationship between acculturation, social support and adjustment will be examined. It seems logically possible that acculturation attitudes will influence the amount of social support which refugees are able to develop, and that this in turn will influence adjustment. The data will therefore be examined for a mediation effect.

\section{Method}

\section{$\underline{\text { Participants }}$}

The sample consisted of 83 adolescent refugees (mean age 15.32 years; $\underline{\mathrm{SD}}=$ 1.49). Fifty one percent were girls and 45 percent boys (four percent missing values). The participants were from the former Republic of Yugoslavia, who migrated to Australia between 1992 to 1998 under the protection of the United Nations High Commissioner for Refugees or through other humanitarian organisations and were consequently granted refugee status in Australia. Most (46\%) migrated to Australia in 1997 and 32\% during 1995/96). The remaining 22\% migrated between 1993/94. About 77\% were born in Bosnia, mainly from Sarajevo, about 20\% in Croatia and the rest in Serbia. The sample consisted of adolescents with Serbian, Muslim and Croatian parentage, although most were of mixed parentage. However, as explained in the introduction, all were raised under the unified pre-war Yugoslav culture and experienced the outbreak of civil war in Yugoslavia, subsequent trauma and refugee 
status. Although about half were new arrivals living in Adelaide, South Australia, for less than a year, only 18\% reported not having good spoken English. An attempt to identify pre-migrational socioeconomic status was made by assessing the level of parental education. About one third had parents with college or University degrees, about one half had parents with trade qualifications or a completed high school degree and the rest had parents who had completed primary school.

\section{$\underline{\text { Instruments }}$}

\section{Demographic information.}

A general demographics questionnaire was administered to collect data such as age, gender, school grade, year of migration to Australia, and place of residence before the refuge.

\section{Social support.}

The three sub-scales from the Social Support Scale for Children were administered (Harter, 1985). These were the sub-scales measuring perceived support and positive regard from parents, classmates and close friends. In total, there were 18 items, six per sub-scale. Harter reported high reliability coefficients for all subscales. The ranges she found for different sample groups and the reliabilities for the present sample are as follows: Parent Social Support, .82 - .88 (present sample, .68);

Classmate Social Support, .74 - .79 (present sample, .77); Close Friend Social Support, .72 - .83 (present sample, .86). Harter reported low to moderate intercorrelations among the subscales, confirming the existence of separate factors. For example for middle school samples the subscale intercorrelations ranged from .27 to .41 . 


\section{Global Self Worth and Peer Social Acceptance.}

The two scales examining adolescents' PSA and GSW were administered. In total, there were ten items, five in each domain. Harter reported satisfactory psychometric properties, with reliability coefficients for PSA ranging from .78 - .90 and for GSW from .80 - .89 for different sample groups (8 through 11th school grades). For the present sample, reliabilities were somewhat lower (.63 for PSA and .71 for GSW. Harter (1985) also reported that a factor analysis indicated the GSW subscale to be qualitatively different from self-descriptions measured in each of the specific domains.

Harter (1988) devised the same question format for both the Social Support Scales for Children and the Adolescent Self-Perception Profile. Each adolescent was presented with each item consisting of two statements reflecting opposite views of oneself. He/she was asked to first decide which statement best described himself/herself and second to indicate the degree to which that statement applied. For each item, scores ranged from 1 ("really true for me”) for the statement that represented lack of social support or competence to 4 ("really true for me”) for the statement reflecting the highest levels of social support or competence.

\section{Acculturation.}

Acculturation was measured by the Acculturation Attitude Scale developed by Sam (1995) after the theoretical model proposed by Berry, Kim and Bosky (1988). The scale has ten items (for example, "I wish to be like an Australian") measuring four different modes of acculturation and different levels of acculturation within each sub-scale. The question leading to statements is: "To what extent do you agree with the following statements?” Items were scored either 5, 4, 3, 2, or 1, where 5 represents full agreement with the statement and 1 represents the strongest disagreement with the 
statement. Where necessary, items were reverse-coded so that high scores indicated a high level of endorsement of the acculturation attitude. Means of items designed to measure the same acculturation attitude were calculated. Sam (1995) found test-retest reliability of the subscales to range between .55 and .74 as well as confirmation of a four factor model of acculturation. Since the scale was developed for a Norwegian population, some necessary minimal changes in the wording were introduced.

\section{Procedures and Data Collection}

Ethical permission for the study was obtained from the Social and Behavioural Research Ethics Committee (Flinders University) and from the Research Unit (Department of Education, Training and Employment, South Australia). The questionnaires were translated into Serbo-Croatian and then back translated into English to determine conceptual and translation equivalence. They were administered in a classroom setting by the examiner (LK) in Serbo-Croatian. Completion of questionnaires took about 20 minutes.

The sample was recruited through contacts with several Adelaide high schools and a special language school for new arrivals. All high schools within Adelaide Metropolitan area, which had potentially large groups of adolescents from the former Yugoslavia, were contacted. Parents of potential participants were informed about the study and their written consent for their child to participate was obtained. A few Year 12 (final year) students were asked to send back questionnaires by mail since they had stopped attending school. In the mainstream high schools a third to a quarter of parents agreed, which is typical of our recent response rates from South Australian schools; teachers sometimes do not distribute letters, while students and/or parents often forget to return consent forms. In addition, in this particular study, a few students of different nationality from the examiner refused to take letters to their 
parents, returning envelopes with written insults to the examiner. In contrast, the majority of parents of children from the special language school consented, probably because of the emphasis that this kind of school has on providing culturally sensitive care for the students. For example, in this school the examiner was advised by the bilingual teacher to provide letters to parents in both Latynic and Cyrillic versions of the alphabet. The inclusion of most available participants from this school would be expected to have improved the representativeness of the total sample. In all schools targeted students represented the minority group although there was a larger number of them in the special language school in comparison with other schools.

\section{Results}

Descriptive Statistics for Social Support and Psychosocial Adjustment Measures

The means and standard deviations for social support, GSW and PSA are shown in Table 1.

(insert Table 1 about here)

\section{$\underline{\text { Relationship Between Social Support and Self-Perception }}$}

To explore the relationship between the measures of social support and psychosocial adjustment, Pearson product-moment correlation coefficients were calculated (Table 2). Positive moderate to strong correlations were found, all correlations being statistically significant. All correlation coefficients for Global SelfWorth and Social Support were higher in comparison with those reported by Harter (1988). The highest correlation was obtained between Global Self-Worth and Classmate Support (Table 2). This may suggest that adolescent refugees have very strong personal investments in classmates, since positive regard from peers is closely related to the way he/she views the self. 
Correlations between the social support scales and the Peer Social Acceptance (PSA) scale (Table 2) were similar to those reported by Harter (1985). The strongest correlation was found between PSA (which measures one's popularity) and Classmate Support. This suggests that youths who perceive themselves to be supported by their peers also appraise themselves as popular and easy to get along with. Moderate positive correlations between Close Friend Support and GSW and PSA (Table 2) indicate that adolescents who have close friends to rely on are more likely to have a better self-perception and also to perceive themselves as more socially acceptable.

\section{(insert Table 2 about here)}

\section{$\underline{\text { Acculturation }}$}

Separation was most strongly endorsed, with $72 \%$ agreeing that they preferred to be in the company of their co-nationals and half agreeing that they should continue to live only within the tradition of their original culture. Just under half agreed with Integration and about one third with Marginalisation. Statements measuring Assimilation attitudes were less endorsed in general, with about 20\% agreeing with statements that they would like people not to know that they are foreigners and that the best way of living would be to live like Australians do.

\section{$\underline{\text { Relationship Between Acculturation Attitudes and Psychosocial Adjustment }}$}

Global-self worth and acculturation attitudes.

Correlations were calculated between Acculturation Attitudes and GSW (Table 3).

\section{(insert Table 3 about here)}

The acculturation variables can be ordered from Integration, the strongest positive correlation, followed by Separation, Assimilation and Marginalisation, the 
strongest negative correlation with GSW (see Table 3). Thus, the order is as hypothesised except that Assimilation has a more negative correlation with GSW than does Separation. To test whether there are any significant differences among the obtained correlations a test for the equality of two dependent correlations was carried out (Steiger, 1980). The results of this analysis indicate that the correlation between GSW and Integration $(\underline{\mathrm{r}}=+.22)$ is significantly different from the two correlations relating GSW and Assimilation $\left(\underline{\mathrm{r}}=-.21, \mathrm{Z}_{1} *=3.38, \underline{\mathrm{p}}<.01\right)$ and Marginalisation $(\underline{\mathrm{r}}=$ -.39, $\left.Z_{1} *=+4.18, \underline{\mathrm{p}}<.01\right)$. The correlation between GSW and Marginalisation was not significantly different from the correlation between GSW and Assimilation. Finally, the correlation between Separation and GSW $(\underline{r}=+.08)$ was significantly different from Marginalisation $\left(Z_{1} *=+2.83, \underline{p}<.01\right)$ but not from Assimilation and Integration. In summary, it is possible to conclude that Integration is more positively related to GSW, whilst Marginalisation and Assimilation are more negatively related to GSW. The relationship between separation and GSW lies somewhere between Integration and Marginalisation.

A standard multiple regression analysis was carried out to further understanding of the relationship between acculturation and GSW. The assumptions underlying the use of multiple regression analysis were not violated. Results are shown in Table 4 . In total, acculturation attitudes can account for about $26 \%$ of variability in GSW $\left(R^{2}=.26\right.$, adjusted $\left.R^{2}=.23, \underline{\mathrm{F}}=7.03, \underline{\mathrm{p}}<.01\right)$. Only Marginalisation and Integration contribute significantly to the variance explained. The relationship between Marginalisation and GSW is negative, indicating that the more a person acculturates thorough Marginalisation relative to how they acculturate through other modes of acculturation, the lower is their GSW. In contrast, the positive relationship between Integration and GSW indicates that the more a person acculturates through 
Integration relative to how they acculturate through other modes of acculturation, the higher is their self-worth. Neither Assimilation nor Separation was found to be a significant predictor of GSW.

\section{(insert Table 4 about here)}

Peer Social Acceptance and Acculturation Attitudes.

A significant negative moderate correlation was found between PSA and both Marginalisation and Assimilation ( $\mathrm{p}<.01$ ) (Table 3). PSA was not significantly correlated with either Separation or Integration.

A test for the equality of two dependent correlations showed that the correlation between PSA and Integration $(\underline{\mathrm{r}}=+.14)$ was significantly different from Marginalisation $\left(\underline{\mathrm{r}}=-.41, \mathrm{Z}_{1} *=3.86, \underline{\mathrm{p}}<.01\right)$, and Assimilation $\left(\underline{\mathrm{r}}=-.30, \mathrm{Z}_{1} *=3.55\right.$, $\underline{\mathrm{p}}<.01)$. The correlation between PSA and Separation $\left(\underline{\mathrm{r}}=.01, Z_{1} *=-2.55, \underline{\mathrm{p}}<.01\right)$ was significantly different from Marginalisation, but not from Assimilation. Further, the correlation between PSA and Assimilation was not significantly different from the correlation between Marginalisation and PSA. These results indicated that Integration is more positively related to PSA, while Marginalisation and Assimilation are more negatively related to PSA. The relationship between Separation and PSA appears to be neither positive nor negative and to lie between Integration and Assimilation.

A standard multiple regression analysis (Table 4) showed that acculturation attitudes such as endorsement of Marginalisation and Integration made a significant contribution to PSA. In total about $26 \%$ of the variance in PSA can be accounted for by Acculturation Attitudes $\left(R^{2}=.26\right.$, adjusted $\left.R^{2}=.22, \underline{F}=6.73, \underline{\mathrm{p}}<.01\right)$. The more a person endorses Marginalisation relative to how they endorse other Acculturation Attitudes, the less they perceive themselves as socially popular. Similarly, the more a person endorses Assimilation relative to other ways of acculturating, the less they see 
themselves to be popular among their peers. On the other hand, the more a person endorses Integration, the more they feel socially popular.

\section{$\underline{\text { Relationship Between Social Support and Acculturation Attitudes }}$}

\section{Close friend support and acculturation attitudes.}

Endorsement of Marginalisation was moderately negatively correlated with Close Friend Support (Table 3). A similar negative correlation was obtained between Assimilation attitudes and Close Friend Support. However, attitudes toward Integration and Separation were not significantly correlated with Close Friend Support.

A standard multiple regression analysis (Table 5) revealed that about $20 \%$ of variance in Close Friend Support can be explained by Acculturation Attitudes $\left(R^{2}=.20\right.$, adjusted $\left.R^{2}=.16, \underline{\mathrm{F}}=5.02, \mathrm{p}<.01\right)$. The negative direction of correlation for both Marginalisation and Assimilation with Close Friend Support indicates that the more a person endorses either Marginalisation or Assimilation relative to other means of acculturation, the less they perceive themselves as capable of forming and maintaining intimate friendships. The opposite could be said for endorsement of Integration: the more a person accepts Integration relative to all other ways of acculturation, the more they see themselves as capable of having close friendships.

\section{(insert Table 5 about here)}

\section{Classmate support and acculturation attitudes.}

The relationship between Classmate Support and acculturation attitudes was significant for Integration, Assimilation and Marginalisation (Table 3). Classmate Support was not significantly correlated with Separation attitudes. Moderate negative correlations were found for both Marginalisation and Assimilation. Endorsement of Integration was positively correlated with Peer Support. A standard multiple 
regression indicated that Acculturation Attitudes together explain about 22\% of the variance in Classmate Support $\left(R^{2}=.22\right.$, adjusted $R^{2}=.18, \underline{\mathrm{F}}=5.63, \underline{\mathrm{p}}<01$ ) (Table 5). Taking into account the positive direction of the correlation between Integration and Classmate Support, it is evident that the more a person accepts Integration relative to other means of acculturation the more they will perceive themselves to be supported by their classmates. On the other hand, the more a person endorses either Marginalisation or Assimilation relative to other ways of acculturation, the less they will perceive themselves supported by their peers.

\section{$\underline{\text { Parental Support and Acculturation Attitudes. }}$}

Correlations were calculated between Parental Support and the Acculturation Attitude scales (Table 3). None of the four Acculturation Attitude scales was significantly related to Parental Support. Since no significant correlations were obtained between the predictor variables and the criterion variable a multiple regression model was not constructed.

$\underline{\text { Social Support as a possible mediator between Acculturation and Psychosocial }}$ $\underline{\text { Adjustment }}$

A hierarchical multiple regression analysis was carried out to test whether acculturation has a direct effect on psychosocial adjustment or an indirect effect through social support (Table 6). With GSW as the criterion variable, at the first step Social Support was introduced into the model. This explained about $58 \%$ of the variance. Acculturation Attitudes were introduced at the next step. When Acculturation Attitudes were introduced into the model, only an additional 3\% of the variance was explained. This compares with a significant $26 \%$ of the variance when Acculturation alone is considered (Table 4). Similar results were obtained using Peer Social Acceptance (PSA) as the criterion variable, with Social Support alone 
accounting for about $45 \%$ of variance and only another $5 \%$ being accounted for by Acculturation Attitudes (Table 6). This compares with a significant 26\% explained by Acculturation Attitudes considered alone (Table 4). These results are consistent with the notion that the effect of Acculturation Attitudes on GSW and PSA is indirect, being mediated by Social Support.

\section{(insert Table 6 about here)}

Finally, it should be noted that the data were analysed separately for new arrivals (who mainly attended the special language school) and longer established refugees (who mainly attended mainstream schools); there were no apparent differences between the two groups.

\section{Discussion}

This study has contributed to acculturation theory by developing a multicultural acculturation model and exploring it within a society that endorses multicultural policy, thus providing to new arrivals a range of options for acculturation. The results are consistent with the proposition that adolescents' acculturation attitudes significantly influence their psychosocial adjustment via their perception of social support.

The adolescent refugees from the former Republic of Yugoslavia, resettled in Australia, strongly supported both separation (predominantly maintaining their original culture), and integration (maintaining the original culture while participating in the host society). However, only integration showed a significant positive relationship with psychosocial adjustment as measured in terms of global self-worth and peer social acceptance. These results support previous research findings indicating that integration offers the best adjustment for both refugees and immigrant youths (Berry, Kim \& Boski, 1988; Dona \& Berry, 1994; Phinney, Chavira \& 
Williamson, 1992 ). This supports the notion that the mental health of refugees is best supported not only by offering opportunities to connect with the host society, but also by accepting the importance of maintaining connections with their native culture.

Separation was not related to any of the examined social support or adjustment variables. Without further study within the Australian context it is difficult to understand the meaning of separation for this particular refugee group. For example, the support for separation attitudes may be related to pre-migration experiences, such as the civil war in Yugoslavia. For these particular adolescents, their ethnicity may have been crucial for survival during years of war. They may therefore be in the early stages of acculturation in which separation can be adaptive. However, it should be noted that a majority who endorsed separation also supported integration, thus suggesting a move towards active participation in the host culture alongside maintenance of their cultural heritage.

Marginalisation and assimilation were given significantly less support. Both marginalisation and assimilation were negatively associated with adjustment. Adolescents who rejected both the culture of origin and the host culture had the lowest adjustment ratings, supporting previous research findings that marginalisation is the least adaptive way of acculturation (Berry, Kim \& Boski, 1988; Khan \& Fua, 1995; Sam \& Berry, 1995).

Similarly, adolescents who endorsed assimilation had low ratings on global self-worth, perceived themselves as less popular among their peers, had fewer close friends, and in general felt less supported by classmates. A possible reason for the unexpected negative relationship between assimilation and adjustment is that these adolescents are in a transitory stage when rejection of one's own ethnic identity precedes establishment of supportive contacts within the host society, leaving the 
youth without a sense of belonging. Previous research suggests that such adolescents may also be more likely to suffer from intrafamily conflicts since they are more ready than their parents to accept the host culture (Rick \& Forward, 1992; Rosenthal, Raniery \& Klimidis, 1996). However, this suggestion might not hold true for this sample, since parental support was not related to acculturation. Social identity theory proposes that our membership of and affiliation to various social groups is central to our identity (Abrams \& Hogg, 1990). It appears that assimilation and marginalisation may equally jeopardise group membership, consequently affecting development of a stable identity in young refugees.

Further, the results of this study confirmed the existence of a positive relationship between social support and adjustment. Adolescents who reported having close friends to rely on had higher global self-worth and perceived themselves to be more socially acceptable. The strong positive relationship found between classmates' support and self-worth stresses the importance of peers. Sandler et al. (1989) reported that support from peers is one important resource that protects children and youths against negative effects of life stressors. Parental support was also a predictor of adjustment, although this was independent of acculturation attitudes.

In comparing the results of this study with other research, it is important to bear some points in mind. First, most previous research has been concerned with psychopathology, and this study used adjustment measures that do not equate with psychopathology (Klimidis et al., 1994). Furthermore, the focus of this study was on self-perceptions rather than behavioural measures such as behavioural acculturation and actual contacts with non-ethnic peers. Finally, while some studies of acculturation have been with migrants in general, this study was specifically with a group of refugees, for whom there are special background issues such as trauma. 
A limitation of the study was the low response rate from the mainstream schools, and while there are a number of possible reasons for this, one might expect 'volunteerism' to play a role in that better-adjusted young people might be more inclined to participate. However, the very high response rate from the special language school should have assisted in this regard, and the study certainly did not fail to include a proportion of students who were less well-adjusted.

In this study several important factors (classmate, close-friend and parent support, integration, assimilation and marginalisation attitudes) were related to adjustment. These findings may be utilised in the development of professional treatment strategies and mental health preventative measures which could be implemented in society (e.g., through schools and ethnic community centres). For example, a programme implemented within the school system may target students who reject both cultures by facilitating their interaction and strengthening connections with both the ethnic culture and the host society. It would be expected that this would enable these young people to develop a greater sense of social support in order to promote good psychosocial adjustment. This suggestion is based on the assumption that changes in acculturation can influence adjustment (via peer social support); while it is also possible that adjustment influences acculturation, Flaskerud and Uman's (1996) findings do suggest a causal relationship between acculturation and adjustment, and the present findings are also consistent with this notion. Evaluation of an intervention such as that proposed here would provide a further test of this proposition.

While the model examined in this study accounts for a significant amount of variance in adjustment, the likely contribution of other factors is acknowledged in the broader-based guiding model shown in Figure 1. Thus, in seeking to promote positive 
adjustment in this population, other issues which may need to be addressed include unresolved trauma, individual characteristics (such as coping style) and societal attitudes toward refugees. 
Table 1

$\underline{\text { Means and Standard Deviations for Social Support, Global Self Worth }}$ $\underline{\text { and Peer Social Acceptance Measures }}$

\begin{tabular}{lll} 
Variable & $\underline{\mathrm{M}}$ & $\underline{\mathrm{SD}}$ \\
\hline Close Friend Supp. & 3.33 & .66 \\
Classmate Supp. & 3.38 & .49 \\
Parental Supp. & 3.38 & .53 \\
Global Self Worth & 3.07 & .62 \\
Peer Social Accept. & 3.01 & .57 \\
\hline
\end{tabular}


Table 2.

Correlations between Social Support Scales, Global Self Worth

and Peer Social Acceptance

\begin{tabular}{lll} 
Variable & GSW & PSA \\
\hline 1. Parental Support & $+.51^{* *}$ & $+.40^{* *}$ \\
2. Classmate Support & $+.72^{* *}$ & $+.63^{* *}$ \\
3. Close Friend Support & $+.59 * *$ & $+.55^{* *}$ \\
& & \\
\hline
\end{tabular}

${ }^{*} \mathrm{p}<.05 \quad * * \mathrm{p}<.01$

Note. The probability of a Type I error was maintained at .05 and .01 levels.

Significances are two tailed 
Table 3.

Correlation Between Acculturation Attitudes, Global Self Worth, Peer Social

$\underline{\text { Acceptance and Social Support Scales }}$

$\begin{array}{llll}\text { Acc. Att. GSW } & \text { PSA } & \text { Close Friend Sup. } & \text { Class. Sup. Parent Sup. }\end{array}$

\begin{tabular}{llllll} 
Integration & $+.22 *$ & +.14 & +.08 & $+.25^{*}$ & +.18 \\
Assimilation & -.21 & $-.30^{* *}$ & $-.26^{*}$ & $-.23^{*}$ & +.07 \\
Separation & +.08 & +.01 & +.13 & -.04 & -.06 \\
Marginalis'n & $-.39 * *$ & $-.41^{* *}$ & $-.36^{* *}$ & $-.29 * *$ & -.16 \\
\hline & & & & & \\
${ }^{* \mathrm{p}<.05}$ & $* * \mathrm{p}<.01$ & & &
\end{tabular}

$\underline{\text { Note. Significances are two tailed }}$ 
Table 4.

Summary of Standard Multiple Regression Analysis for Acculturation Attitude

Variables Predicting Global Self Worth and Peer Social Acceptance ( $\mathrm{N}=83$ )

Acc. Att.

GSW $\underline{B}$

PSA $\underline{B}$

$\beta$

\begin{tabular}{lllll} 
Integration & +.21 & $+.38^{* *}$ & +.13 & $+.27^{*}$ \\
Marginalisation & -.16 & $-.32^{* *}$ & -.15 & $-.33^{* *}$ \\
Assimilation & -.09 & -.20 & -.11 & $-.27^{*}$ \\
Separation & +.16 & +.16 & +.01 & +.02 \\
\hline
\end{tabular}

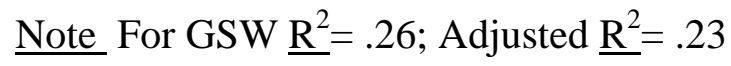

$\underline{\text { Note }}$ For PSA $\underline{\mathrm{R}^{2}}=.26$; Adjusted $\underline{\mathrm{R}^{2}}=.22$

$* \mathrm{p}<.05 \quad * * \mathrm{p}<.01$ 
Table 5.

$\underline{\text { Summary of Standard Multiple Regression Analysis for Acculturation Attitude }}$

Variables Predicting Close Friend Support and Classmate Support ( $\mathrm{N}=83$ )

Acc. Att.

Close Friend S. Classmate S.

B $\quad \beta$

B $\quad \beta$

\begin{tabular}{lcccc} 
Integration & +.15 & $+.25^{*}$ & +.16 & $+.38^{* *}$ \\
Marginalisation & +-.14 & $-.27^{*}$ & -.09 & $-.22^{*}$ \\
Assimilation & -.11 & $-.23^{*}$ & -.10 & $-.27^{*}$ \\
& & & & \\
Separation & +.10 & +.16 & +.02 & +.04 \\
\hline
\end{tabular}

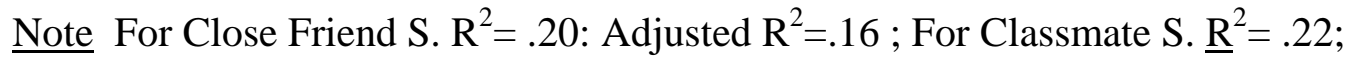

Adjusted $\underline{\mathrm{R}}^{2}=.18$

${ }^{*} \mathrm{p}<.05 \quad * * \mathrm{p}<.01$ 
Table 6.

$\underline{\text { Summary of Hierarchical Regression Analysis for Variables }}$

$\underline{\text { Predicting Global Self-Worth (GSW) and Peer Social }}$

Acceptance (PSA) $(\mathrm{N}=83)$

$\begin{array}{llll}\text { GSW } & & \text { PSA } \\ \text { B } & \beta & \underline{B} & \beta\end{array}$

Step 1

$\begin{array}{lllll}\text { Close friend S. }+.27 & +.29 * * & +.25 & +.29 * * \\ \text { Classmate S. } & +.55 & +.13^{* *} & +.46 & +.39 * * \\ \text { Parental S. } & +.23 & +.20 * & +.12 & +.11\end{array}$

Step 2

\begin{tabular}{llllll} 
Integration & +.08 & +.14 & & +.04 & +.07 \\
Marginalis’n & -.06 & -.13 & -.07 & -.17 \\
Assimilation & -.03 & -.06 & -.06 & -.14 \\
& & & & \\
Separation & .07 & .11 & -.01 & -.02 \\
\hline
\end{tabular}

Note For Global Self-Worth $\underline{\mathrm{R}}^{2}=.58$ for Step $1 ; \Delta \underline{\mathrm{R}}^{2}=.03$ for Step 2.

For Peer Social Acceptance $\underline{\mathrm{R}}^{2}=.45$ for Step $1 ; \Delta \underline{\mathrm{R}}^{2}=.05$ for Step 2

$* \mathrm{p}<.05 \quad * * \mathrm{p}<.01$ 
Figure 1. Factors thought to influence the global self worth and

peer social acceptance of adolescent refugees

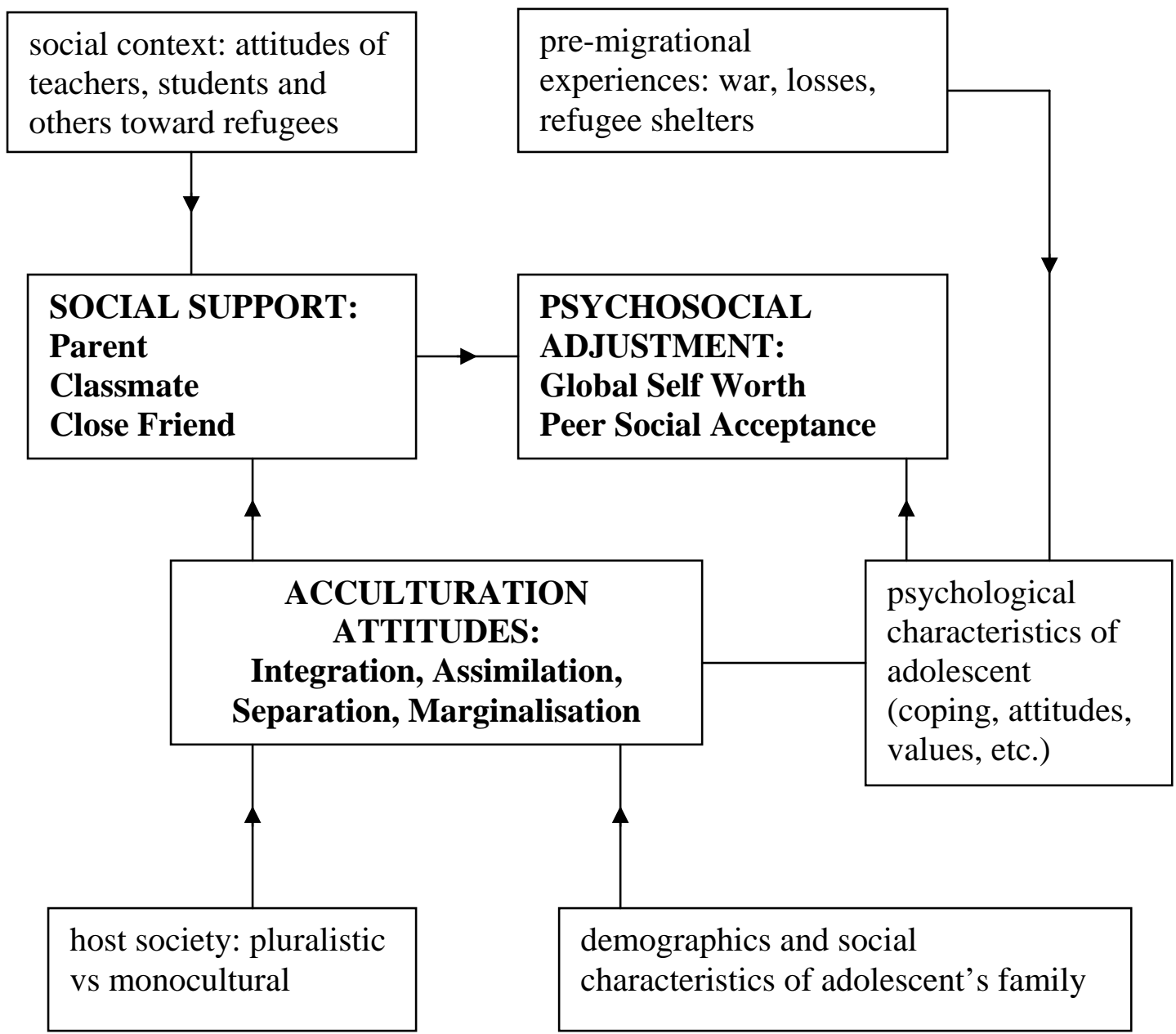




\section{REFERENCES}

Abrams, D., \& Hogg, M.A. (1990). Social identity theory. Exeter: Harvester, Wheatsheaf.

Berry, J. W. (1984). Cultural relations in plural societies: Alternative to segregation and their sociopsychological implications. In N. Miller \& M. Brewer (Eds.), Group in Contact. New York: Academic Press.

Berry, J. W., Kim, U., \& Boski, P.(1988). Psychological acculturation of immigrants In Y. Y. Kim \& W. B. Gudykunst (Eds.), Cross-cultural adaptation: Current approaches. CA: SAGE Publications.

Bagwell, C. L., Newcomb, A. F., \& Bukowski, W. M. (1998). Preadolescent friendships and peer rejection as predictors of adult adjustment. $\underline{\text { Child }}$ Development, 69, 140-153.

Branch, C.W. (2001). The many faces of self: Ego and ethnic identities. Journal of Genetic Psychology, 162, (4), 412.

Cheung, P. (1995). Acculturation and psychiatric morbidity among Cambodian refugees in New Zealand. International Journal of Social Psychiatry, 41, 108-119.

Cooper, C.R., Jackson, J.F., Azmitia, M., \& Lopez, E. (1998). Multiple selves, multiple worlds: Three useful strategies for research with ethnic minority youth on identity, relationships, and opportunity structures. In: V.C. McLoyd \& L. Steinberg, Studying minority adolescents: Conceptual, methodological and theoretical issues, pp. 111-125. Mahwah, NJ: Lawrence Erlbaum.

Department of Immigration and Multicultural Affairs (1998). Fact Sheet 40 Public Affairs Section, Canberra, Australian Capital Territory: Author. 
Dona, G., \& Berry, J (1994). Acculturation attitudes and acculturation stress of Central American refugees. International Journal of Psychology, 29 (1) 57-70.

Flaskerud, J,.\& Uman, G. (1996). Acculturation and its effect on self-esteem among immigrant Latina Women. Behavioral Medicine, 22 (3), 123-133.

Gans, H. J. (1997). Toward a reconciliation of “Assimilation” and "Pluralism”: The interplay of acculturation and ethnic retention. International Migration Review, 31, 875-892

Garmezy, N. (1983). Stressors of childhood. In N. Garmezy \& M. Rutter, (Eds.), Stress, Coping, and Development in Children. New York: McGraw-Hill.

Georgas, J., Berry, W. J., Shaw, A., Christakopulou, S., \& Mylonas, K. (1996). Acculturation of Greek family values. Journal of Cross Cultural Psychology, $\underline{27}$ (3), 329-338.

Grassby, A.J. (1973). A multi-cultural society for the future. Canberra: Australian Government Publishing Service.

Harter, S. (1985). Manual for the social support scale for children. University of Denver, Denver.

Harter, S. (1988). Manual for the self-perception profile for adolescents. University of Denver, Denver.

Huang, K., Leong, F. T., \& Wagner, N. S. (1994). Coping with peer stressors and associated dysphoria: Acculturation differences among Chinese-American children. Counselling Psychology Quarterly, 7, 53-68.

Hurtado, S., \& Carter, D. F. (1997). Effects of college transition and perceptions of the campus racial climate on Latina college students' sense of belonging. Sociology of Education, 70, 324-345. 
Jenkins, S. (1997). Australian multiculturalism: What is the National agenda. Unpublished Honours Dissertation, Adelaide University.

Khan, M., \& Fua, C. (1995). Children of South Sea Island immigrants to Australia: Factors associated with adjustment problems. International Journal of Social Psychiatry, 41 (1), 55-73

Kovacev, L. (1994) Mehanizmi prevladavanja kod zena izbeglica, (Coping strategies among women refugees) Honours Thesis. Yugoslavia: Belgrade University.

Klimidis, S., Stuart, G., Minas, I. G., \& Ata, A. W. (1994). Immigrational strategies and gender effects on psychopathology and self-concept in adolescents: A test of the migration morbidity hypothesis. Comprehensive Psychiatry, 36 (5), 393-404.

Kwon, P (1995). Application of social cognition principles to treatment recommendations for ethnic clients; The case of Asian Americans. $\underline{\text { Clinical }}$ Psychology Review, 15 (7), 613-629.

LaFromboise, T., Coleman, H. L., \& Gerton, J. (1993). Psychological impact of biculturalism: Evidence and theory. Psychological Bulletin, 114, 395-412.

Liebkind, K. (1996). Acculturation and Stress: Vietnamese refugees in Finland, Journal of Cross Cultural Psychology, 27 (2),161-180.

Momartin, S., Silove, D., Manikavasagar, V., \& Steel, Z. (2002). Range and dimensions of trauma experienced by Bosnian refugees resettled in Australia. Australian Psychologist, 37, 2, 149-155.

Myers, S. (1999). Childhood migration and social integration in adulthood. Journal of Marriage and the Family, 61, 774-789. 
Nguyen, N. A., \& Williams, H. L. (1989). Transition from east to west: Vietnamese adolescents and their parents. Journal of American Academy and Child Adolescent Psychiatry, 4, 505-515

Office of Multicultural Affairs.(1988). Multiculturalism and immigration. Canberra, AGPS: Author.

Orshan, S.A. (1996). Acculturation, perceived social support, and self-esteem in Primagravida Puerto Rican teenagers. Western Journal of Nursing Research, $\underline{18}$ (4), 460-473

Padilla, A. M., Wagatsuma, Y., \& Lindholm, K. (1985). Acculturation and personality as predictors of stress in Japanese and Japanese-Americans. The Journal of Social Psychology, 125, 295-305

Pernice, R., Brook, J. (1996). Refugees’ and immigrants’ mental health: Association of demographics and post-immigrational factors. Journal of Social Psychology, 136 (4), 511-519.

Phinney. J.S., \& Alipura, L. (1990). Ethnic identity in older adolescents from four ethnic groups. Journal of Adolescence, 3, 171-184.

Phinney, J. S., Chavira, V., \& Williamson, L. (1992). Acculturation attitudes and selfesteem among high school and college students. Youth and Society, 23, 299-312.

Phinney, J. S., Lochner, B. T,.\& Murphy, R. (1990). Ethnic identity development and psychological adjustment in adolescence. In A. R. Stiffman \& L. E. Davis (Eds.), Ethnic issues in adolescent mental health. CA: Sage.

Pope, A. W., McHale, S. M., \& Craighead, E. (1988). Self-esteem enhancement with children and adolescents. Sydney: Pergamon Press. 
Rick, K., \& Forward, J. (1992). Acculturation and perceived intergenerational differences among Hmong youth. Journal of Cross-Cultural Psychology, 23, 85-94.

Roer-Strier, D. (1996). Coping strategies of immigrant parents: Directions for family therapy. Family Process, 35, 363-376.

Rosenthal, D. A., \& Feldman, S. S. (1992). The nature and stability of ethnic identity in Chinese youth: Effects of Length of Residence in Two Cultural Contexts. Journal of Cross-Cultural Psychology, 23, 214-227.

Rosenthal, D., Ranieri, N., \& Klimidis, S.(1996). Vietnamese adolescents in Australia: Relationship between perceptions of self and parental values, intergenerational conflict, and gender dissatisfaction. International Journal of Psychology, 31 (2), 81-91.

Sack, W., Clarke, G., \& Seely, J. (1996). Multiple forms of stress in Cambodian adolescent refugees. Child Development, 67 (1),107-116.

Sam, D. L. (1995). Acculturation attitude among immigrants as a function of perceived parental attitudes toward cultural change. Journal of Early Adolescence, 15, 238-258

Sam, D. L. \& Berry, J. W. (1995). Acculturative stress among young immigrants in Norway. Scandinavian Journal of Psychology, 36, 10-21.

Sandler, I., Miller, P., Short, J., \& Wolnik, S. (1989). Social support as a protective factor for children in stress. In D. Belle, (Eds.), Children’s Social Networks and Social Supports. Chichester: Wiley.

Sasao, T., \& Chun, C. A. (1994). After the Sa-i-gu (April 29) Los Angeles riots: Correlates of subjective well-being in the Korean-American community. Journal of Community Psychology, 22, 136-152. 
Solberg, V., Valdez, J., \& Villavreal, P. (1994). Social support, stress and Hispanic college adjustment: Test of a diathesis-stress model. Hispanic Journal of Behavioural Sciences, 16, 230-239.

Shute, R., DeBlasio, T., \& Williamson, P. (2002). Social support satisfaction of Australian children. International Journal of Behavioral Development, 26 (4), 318-326.

Steiger, J.H. (1980). Tests for comparing elements of a correlation matrix. Psychological Bulletin, 87 (2), 245-251.

Werner, E. E., \& Smith, R. S. (1982). Vulnerable but invincible: A longitudinal study of resilient children and youth. New York: McGraw Hill.

Yu, P., \& Berryman, D. (1996). The relationship among self-esteem, acculturation and recreation participation of recently arrived Chinese immigrant Adolescents. Journal of Leisure Research, 28, 251-273

Acknowledgements

We sincerely thank the schools and young people who participated in this project, and Dr. Paul Williamson for his invaluable statistical advice. 